\title{
Signature of the 27-day oscillation in the MLT tides and its relation with solar radiation at low latitudes
}

\author{
Amitava Guharay ${ }^{1 *}$, Paulo Prado Batista ${ }^{2}$, Ricardo Arlen Buriti ${ }^{3}$ and Nelson Jorge Schuch ${ }^{4}$
}

\begin{abstract}
The modulation of the dominant atmospheric tides (i.e. diurnal, semidiurnal and terdiurnal) in the mesosphere and lower thermosphere (MLT) is investigated using long-term meteor wind database from three Southern hemispheric low-latitude locations, São João do Cariri $\left(7.4^{\circ} \mathrm{S}, 36.5^{\circ} \mathrm{W}\right)$, Cachoeira Paulista $\left(22.7^{\circ} \mathrm{S}, 45^{\circ} \mathrm{W}\right)$ and Santa Maria $\left(29.7^{\circ} \mathrm{S}\right.$, $53.7^{\circ} \mathrm{W}$ ). The spectral analysis reveals an evident and intermittent signature of a 27 -day oscillation in the tidal amplitudes. Relationship between the 27-day tidal modulation in the MLT and solar rotation is looked into utilizing solar UV flux (Lyman-a) that indicates a conspicuous linkage of the tides with the solar short-term variability. The strong correlation between the solar variability and tidal modulation in the concerned period with positive lags at certain intervals may indicate predominate solar influence on the MLT tides. Potential involvement of the lower, middle and upper atmospheric dynamics and chemistry to support the observed oscillation feature is deemed plausible.
\end{abstract}

Keywords: 27-day oscillation, Tides in the MLT, Meteor radar observations

\section{Introduction}

Atmospheric tides are one of the most prominent dynamical entities that transfer significant amount of energy from the lower atmosphere to mesosphere and lower thermosphere (MLT) and modify the ambient dynamical condition considerably (Miyahara et al. 1993; Hagan and Forbes 2002). Periodic solar heating of the atmosphere is the prime reason for the generation of these tides containing periods of several subharmonics of a solar day, i.e. 24, 12, 8, $6 \mathrm{~h}$ and so on (Batista et al. 2004; Guharay et al. 2011, 2013a, 2015, 2018). In general, the amplitudes of the tides with higher periods tend to be very small and the dominant tidal manifestation in the atmosphere occurs in the periods, $24 \mathrm{~h}$ (diurnal), $12 \mathrm{~h}$ (semidiurnal) and $8 \mathrm{~h}$ (terdiurnal) tides. The diurnal tide generally dominates in the low latitudes and semidiurnal tide takes over the former in the mid and high latitudes

\footnotetext{
*Correspondence: guharay@prl.res.in

${ }^{1}$ Space and Atmospheric Sciences Division, Physical Research Laboratory, Ahmedabad, GJ, India

Full list of author information is available at the end of the article
}

(Manson et al. 1989). Although the amplitude of the terdiurnal tide is normally much smaller than the other two components, it can be significantly large at times (Thayaparan 1997).

Since Sun is the major source of energy of the Earth, it has potential to control and modify various physical, chemical and dynamical processes occurring at various levels in the Earth atmosphere. The prominent signature of the variability of the solar UV irradiance can be observed in the atmosphere with periodicities, 11 years (solar cycle), 1 year (seasonal) and 27 days (Carrington rotation) as investigated by the past investigators from various locations over the globe (Suh and Lim 2006; Guharay et al. 2009, 2017, 2019 and references therein). A major portion of the solar UV flux is absorbed in the middle atmosphere. The short-term solar UV flux variability can be as large as $25 \%$ during solar active condition (Schanz et al. 2016). The solar 11-year oscillation was reported mostly in the stratospheric ozone as the photochemical processes associated to ozone production are very sensitive to the solar UV radiation (Chandra and McPeters 1994; Hood 1997). 
The evident feature of the solar 27-day oscillation was found in various atmospheric parameters, e.g. lightning activity (Füllekrug and Fraser-Smith 1996), ozone concentration (Hood, 1997; Ross and Walterscheid 1991), temperature (Hood 2016), wind (Huang et al. 2015; Guharay et al. 2017), ionospheric plasma (Pancheva et al. 1991; Ma et al. 2012; Ren et al. 2018), etc. The 27-day oscillation is most pronounced in the Lyman- $\alpha$ line (UV band) although it is present in the total solar irradiance. The evident signature of the 27-day oscillation was also reported in the long-period planetary wave activities in the stratosphere (Ebel et al. 1981; von Savigny et al. 2019).

Using Whole Atmosphere Community Climate Model (WACCM), Schanz et al. (2016) investigated the effect of solar irradiance on the zonal wind variability. They concluded that the solar short-term variability driven atmospheric perturbations might interact with atmospheric internal oscillation modes or background mean flow to cause associated changes in the ambient dynamical condition. With the help of space-based observations from the Solar Occultation for Ice Experiment (SOFIE) onboard Aeronomy of Ice in the Mesosphere (AIM) satellite, Thomas et al. (2015) found evident signature of the solar 27-day oscillation in the water vapor and temperature that could influence the chemistry of the polar mesospheric cloud (PMC) formation. Luo et al. (2001) studied the longer period (20-40 days) wind oscillation characteristics in the MLT using multi-station radar observations at mid and high latitudes in the Northern hemisphere and inferred that the 27 -day periodicity in the wind was a manifestation of solar short-term variability.

As mentioned before, the 27-day oscillation was evident in various atmospheric quantities. However, relationship between the solar 27-day signal and the dominant atmospheric tides is not looked into extensively and hence our understanding regarding the underlying processes is very limited. Furthermore, different signatures of the 27-day signal in the MLT were obtained by the past investigators. Previous studies interpreted that the concerned oscillation in the middle atmosphere was (i) linked with the solar rotation (Pancheva et al. 1991; Luo et al. 2001; Guharay et al. 2017), (ii) a component of the lower atmospheric intraseasonal oscillations (Huang et al. 2015) and (iii) an inherent mode of the atmosphere (Schanz et al. 2016). In the present work, an extensive investigation related to the imprint of the 27-day signal on the dominant MLT tides and its relationship with the solar rotation is carried out using meteor radar wind observations from three low-latitude Southern hemispheric stations, São João do Cariri $\left(7.4^{\circ} \mathrm{S}, 36.5^{\circ} \mathrm{W}\right)(\mathrm{CA})$, Cachoeira Paulista $\left(22.7^{\circ} \mathrm{S}, 45^{\circ} \mathrm{W}\right)(\mathrm{CP})$ and Santa Maria $\left(29.7^{\circ} \mathrm{S}, 53.7^{\circ}\right.$ W) (SM).

\section{Instrument and data analysis Meteor radar}

The meteor radar systems in the current study are a SKiYMET type, operating at a frequency of $35.24 \mathrm{MHz}$. It uses peak power of $12 \mathrm{~kW}$, pulse width of $13 \mu \mathrm{s}$ and pulse repetition frequency of $2 \mathrm{kHz}$. It consists of a threeelement transmitting antenna and five phase-coherent, two-element Yagi antennas aligned along two orthogonal baselines with a center antenna common to the both for detecting meteor echoes. Since both receiving and transmitting antennas have a large angle of acceptance, the radar records meteor echoes in all zenith and azimuth directions. The radar detects around 5000 meteor echoes per day to estimate angular position, range and radial velocity. Details of the radar operation and method of horizontal wind velocity estimation can be found in the past literature (Hocking et al. 2001).

In the present study, horizontal winds from the three radar systems are used with temporal resolution of $1 \mathrm{~h}$ and vertical resolution of $3 \mathrm{~km}$ in the MLT $(80-100 \mathrm{~km})$. The amplitude and phase of the dominant tidal components are estimated using least square fit method considering a data window of 4 days, which is progressively shifted by a day to estimate daily tidal parameters using Eq. 1.

$$
Y(t)=Y_{0}+\sum_{n=1,2,3} A_{n} \sin \left[\frac{2 \pi n}{24}\left(t-\phi_{n}\right)\right]
$$

where $n=1,2,3$ denote diurnal, semidiurnal and terdiurnal components, $t$ is the time in hour, $A$ is the amplitude of the tide, $\phi$ is the phase of the tide, $Y_{0}$ is the mean value within the fitting window and $Y(\mathrm{t})$ is the zonal/ meridional wind. The tidal parameters are estimated for the cases where at least 48 data points (twice the period of the diurnal tide) are available. However, one should note that selection of 4-day window can give two or three consecutive ambiguous daily outputs depending on the pattern of the available and missing data. We have thoroughly checked the same with our observational intervals used for the present study and do not find any such case. Since the quasi-2-day wave was found to be very active at times over the present sites (Guharay et al. 2013b), it is removed from the original time series before estimating the tidal parameters.

The daily tidal amplitudes estimated from the available data spans, 2004-2008 (CA), 1999-2018 (CP), 2004-2010 (SM), are undergone wavelet analysis using Morlet as a mother wavelet (Torrence and Compo 1998) to obtain the spectra of the modulating periodicities. Utilizing the wavelet spectra of all three sites, intervals with evident 27-day modulation are identified and used for 
further analysis. The 27-day modulation is mostly found in the tidal amplitudes derived from the zonal wind and hence only zonal amplitudes are utilized in the present study. The interval window is restricted to 62 days ( $\sim$ more than twice the period of interest) to avoid long data gaps and to maintain uniformity among the selected cases. The details of the selected intervals when 27-day modulations of the tidal amplitudes in the zonal wind are prominent are provided in Table 1 . Overall, 3 cases at $\mathrm{CA}, 9$ cases at $\mathrm{CP}$ and 3 cases at SM containing all the tidal components (diurnal, semidiurnal and terdiurnal) are identified and analyzed in the present work as illustrated in Table 1. The 27-day modulated amplitudes and corresponding phases in the tides are estimated by utilizing least square fit on the daily tidal amplitudes for each interval (window of 62 days) and tidal component independently.

\section{Solar Lyman- $a$ flux}

To find out the solar linkage of the observed 27-day modulation in the tidal amplitudes obtained from the zonal wind in the MLT, solar Lyman- $\alpha$ flux $(121.6 \mathrm{~nm})$ data provided by the Laboratory for Atmospheric and Space Physics (LASP), University of Colorado, corresponding to the selected intervals are analyzed. For the present purpose, the Lyman- $\alpha$ data with temporal resolution 1 day are utilized.

The dominant periodicities in the solar flux during the selected intervals are estimated using wavelet analysis. To determine the relationship between the solar flux and 27-day oscillations in the MLT tidal amplitudes in

Table 1 Details of the selected intervals showing evident signature of the 27-day modulation of the tidal amplitude in the zonal wind

\begin{tabular}{llll}
\hline Station & Tidal component & Interval (DY) & Year \\
\hline São João do Cariri $\left(7.4^{\circ} \mathrm{S}\right.$, & Diurnal & $220-281$ & 2004 \\
$\left.36.5^{\circ} \mathrm{W}\right)$ & Semidiurnal & $065-126$ & 2008 \\
& Terdiurnal & $160-221$ & 2008 \\
Cachoeira Paulista $\left(22.7^{\circ} \mathrm{S}\right.$, & Semidiurnal & $110-171$ & 2002 \\
$\left.45^{\circ} \mathrm{W}\right)$ & Semidiurnal & $110-171$ & 2003 \\
& Terdiurnal & $140-201$ & 2003 \\
& Diurnal & $235-296$ & 2004 \\
& Diurnal & $060-121$ & 2008 \\
& Diurnal & $250-311$ & 2012 \\
& Terdiurnal & $250-311$ & 2012 \\
& Semidiurnal & $260-321$ & 2013 \\
& Diurnal & $210-271$ & 2014 \\
Santa Maria $\left(29.7^{\circ}\right.$ S, 53.7 $\left.\mathrm{W}\right)$ & Terdiurnal & $155-216$ & 2006 \\
& Diurnal & $240-301$ & 2008 \\
& Semidiurnal & $105-166$ & 2010 \\
\hline
\end{tabular}

the zonal wind, cross-correlation analysis is carried out. Before carrying out the cross-correlation analysis, both series are undergone a bandpass filter with cutoffs at 24 and 31 days to consider the quasi-27-day oscillation.

\section{Results}

The daily tidal amplitudes at $90 \mathrm{~km}$ and Ly- $\alpha$ flux (unit $=10^{11}$ photons $/ \mathrm{cm}^{2} / \mathrm{s}$ ) for the selected intervals, i.e. diurnal (060-121 DY, 2008) at CP, semidiurnal (065-126 DY, 2008) at CA and terdiurnal (150-211 DY, 2006) at $\mathrm{SM}$, respectively (DY represents day of the year). In general, solar flux exhibits visually identifiable crests/troughs with approximate periodicity $\sim 30$ days. Tidal amplitudes show more fluctuations in the temporal profiles. Although diurnal tide exhibits less prominent 30 -day periodicity, such behavior is not very clear in other tidal components. To determine the exact periods, wavelet analysis is carried out. Figure $1 \mathrm{~d}-\mathrm{f}$ shows the wavelet power spectra of the tidal amplitudes in the zonal wind at $90 \mathrm{~km}$ for the corresponding intervals. The bold lines represent the 95\% significance level. Evident from the plots is conspicuous periodicity near 27-day in all the spectra. In addition, smaller but significant patch of 10-day period is also present in the semidiurnal and terdiurnal components indicating a possible coupling with a 10-day planetary wave. However, since the theme of the present work is 27-day oscillation, we will not discuss any other waves/ oscillations in the rest of the manuscript. One may note a slightly lesser periodicity in the tidal amplitudes as compared to the Ly- $\alpha$. The small difference in the observed periods may be ascribed to direct bearing of the solar signature in case of solar flux and subsequent imprint on the atmospheric wind/tides (i.e. atmospheric response to the solar forcing). Figure $1 \mathrm{~g}-\mathrm{i}$ shows the wavelet power spectra estimated from the solar Lyman- $\alpha$ flux corresponding to the above-mentioned intervals. It is interesting to note that all the three solar spectra exhibit dominant power near 27-day consistent with the spectra of the tidal amplitudes in the zonal wind implying a possible link between them. However, during 150-211 DT, 2006, the period in the Lyman- $\alpha$ spectra is slightly higher than the same of the tidal spectrum in the zonal wind. Behavior of the 27-day oscillation in the tidal amplitudes and their association with the solar flux will be investigated in the following part of the paper.

Figure 2a-c shows the 27-day modulated amplitudes of diurnal tide at CA, CP and SM, respectively. Larger number of cases is visible at $\mathrm{CP}$ as compared to the other sites due to longer database. At CA, gradual increase of amplitude is visible although there is a saturation tendency at bottom and top altitudes. At CP, vertical behavior of the modulated amplitudes for the 4 years is not smooth unlike CA. Broadly, the variability can be considered as 

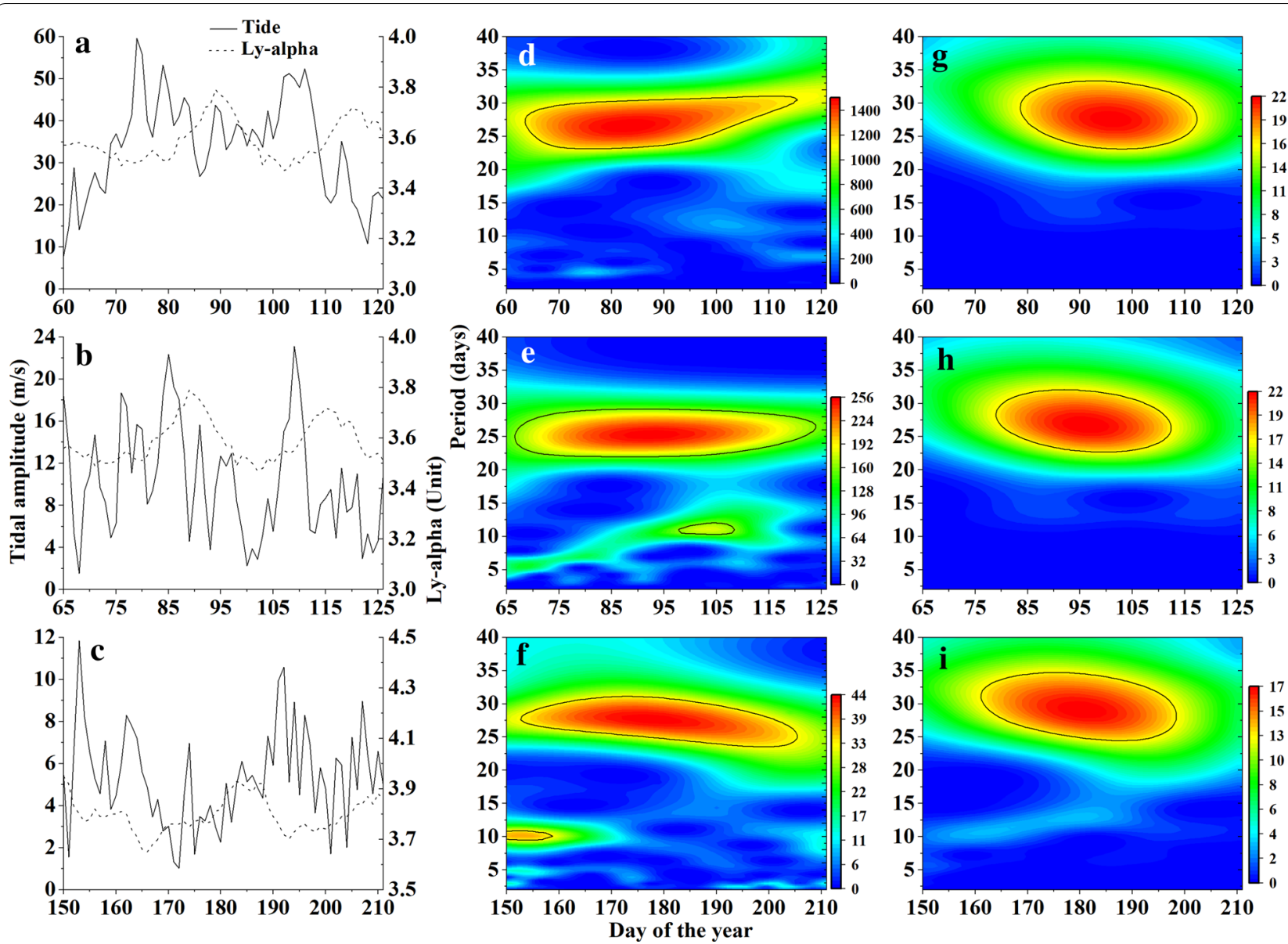

Fig. 1 Daily tidal amplitudes and Ly- $a$ flux (unit $=10^{11}$ photons $/ \mathrm{cm}^{2} / \mathrm{s}$ ) at $90 \mathrm{~km}$ for (a) diurnal tide during 060-121 DY, 2008 at CP, (b) semidiurnal tide during 065-126 DY, 2008 at CA and (c) terdiurnal tide during 150-211 DY, 2006 at SM. Corresponding wavelet spectra estimated from the daily amplitude in the zonal wind for (d) diurnal tide, (e) semidiurnal tide and (f) terdiurnal tide. Wavelet spectra computed from the daily Ly- $a$ data shown in plots $\mathbf{g}, \mathbf{h}$ and $\mathbf{i}$ corresponding to the intervals of $\mathbf{a}, \mathbf{b}$ and $\mathbf{c}$, respectively

two types, (i) increasing trend with altitude (2004 and 2014) and (ii) peaking near $87-90 \mathrm{~km}$ and decreasing upward as well as downward (2008 and 2012). The maximum 27-day modulated tidal amplitude is observed in 2008 near $87-91 \mathrm{~km}$. Except 2012, all the profiles exhibit decreasing amplitude with respect to altitude at the bottom. On the other hand, at SM a single profile shows alternate maxima and minima in the MLT with overall decreasing trend.

Figure $2 \mathrm{~d}-\mathrm{f}$ plots the 27-day corresponding phases of the diurnal tidal modulation at the three stations. The phase profiles over all the locations show relatively smoother behavior as compared to the amplitudes depicted before. It should be noted that the phases are basically estimated considering initial time similar to the method of Guharay et al. (2017), and hence, phase and oscillation propagation directions are similar. In general, the phase profile at CA shows slightly negative phase gradient indicating downward oscillation progression.
Overall, the phase profiles at CP exhibit upward phase/ oscillation propagation except 2014, although the regions $81-84$ and $87-100 \mathrm{~km}$ individually show upward phase/ oscillation progression in 2014. At SM, the phase profile shows almost consistent upward phase/oscillation progression.

Similarly, the 27-day modulated amplitude and corresponding phase profiles of the semidiurnal tide are shown in Fig. 3. Although the amplitude shows monotonically increasing behavior in the MLT, it decreases sharply at the top. Interestingly, at $\mathrm{CP}$ all the profiles show two prominent troughs around $84-87$ and $93-96 \mathrm{~km}$ and one crest within $90-93 \mathrm{~km}$. The maximum modulated amplitude is observed at the top in 2003. The amplitude profile at SM shows "S" kind of feature with a crest at $84 \mathrm{~km}$ and trough at $93 \mathrm{~km}$.

The corresponding 27-day semidiurnal phase profile at CA shows decreasing trend or downward phase/ oscillation progression. However, at $\mathrm{CP}$ all the three 


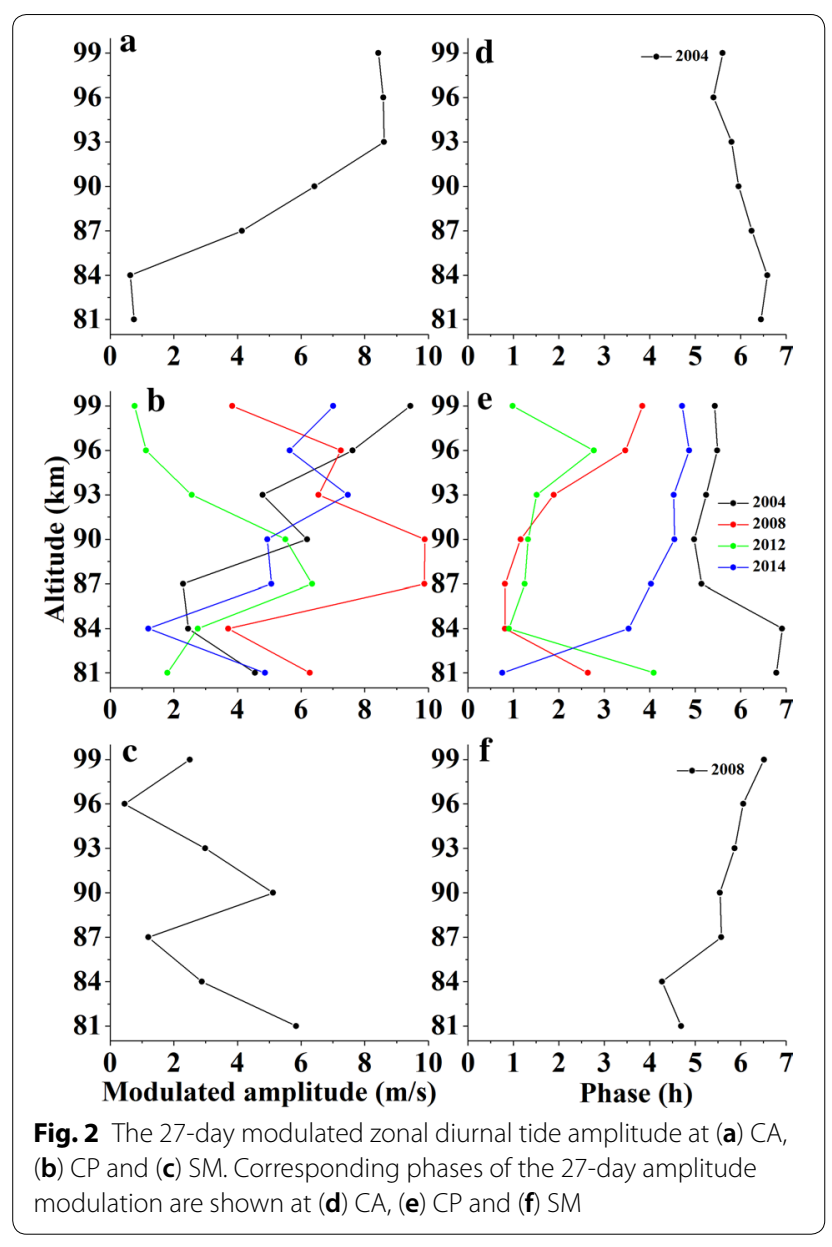

profiles exhibit upward phase/oscillation propagation. At SM, the phase behavior is different at upper and lower MLT as the phase gradient is slightly negative at upper altitudes and slightly positive at lower MLT with a sharp positive change around $90-93 \mathrm{~km}$.

In a similar fashion, the 27-day modulated amplitudes and corresponding phases of the terdiurnal tide are plotted in Fig. 4. The amplitude at CA shows almost linear alternate increase and decrease with a peak at $87 \mathrm{~km}$ and dip at $93 \mathrm{~km}$. At CP, the amplitude profiles are generally zig-zag in nature. However, the profile in 2003 shows overall increasing trend and no clear trend can be evinced in 2012. On the other hand, at SM almost linear increasing amplitude at lower MLT from 84 to $93 \mathrm{~km}$ and decreasing trend hereafter can be noted.

The phase variation at $\mathrm{CA}$ shows overall small negative gradient implying downward oscillation progression. The oscillation propagation direction at $\mathrm{CP}$ can be found to be upward from $84 \mathrm{~km}$ in 2003. However, in 2012 oscillation propagation is upward in the lower MLT and downward hereafter. At SM, small positive gradient of the

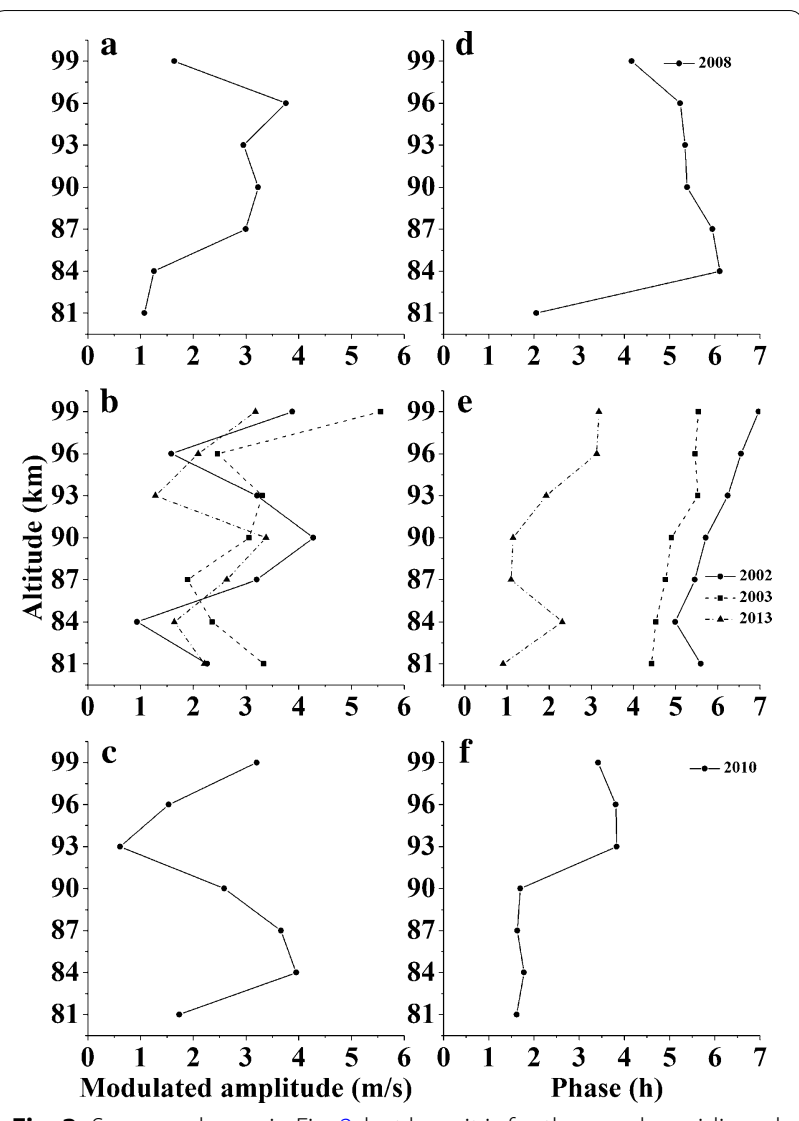

Fig. 3 Same as shown in Fig. 2, but here it is for the zonal semidiurnal tide

phase profile can be observed implying upward oscillation progression.

So far, the characteristic features of the 27-day modulation on the dominant tides in the MLT are investigated. To find out its link (if any) with the solar radiation, crosscorrelation analysis is carried out and the results are presented in the subsequent paragraphs.

The cross-correlation coefficient $(r)$ between the filtered solar Lyman- $\alpha$ flux and tidal amplitudes in the zonal wind is shown in Fig. 5a-c. The values of $r$ greater than 0.5 (significant with $\alpha=0.01$ ) are considered for existing relationship between the two variables. According to the $r$ values, there exists a strong relation between the two variables as found at lower MLT at CA. Although $r$ decreases at higher altitude, significant relationship exists in the MLT. At CP, almost constant and strong correlation is found in all the profiles over the whole range except at the bottom and top altitude bins. On the contrary, no evident correlation is found among the two variables except at 87 and $96 \mathrm{~km}$ at SM.

The corresponding cross-correlation lag profiles are shown in Fig. $5 d-f$. Here, the positive lag represents that the oscillation in the solar flux leads the same of the tidal 


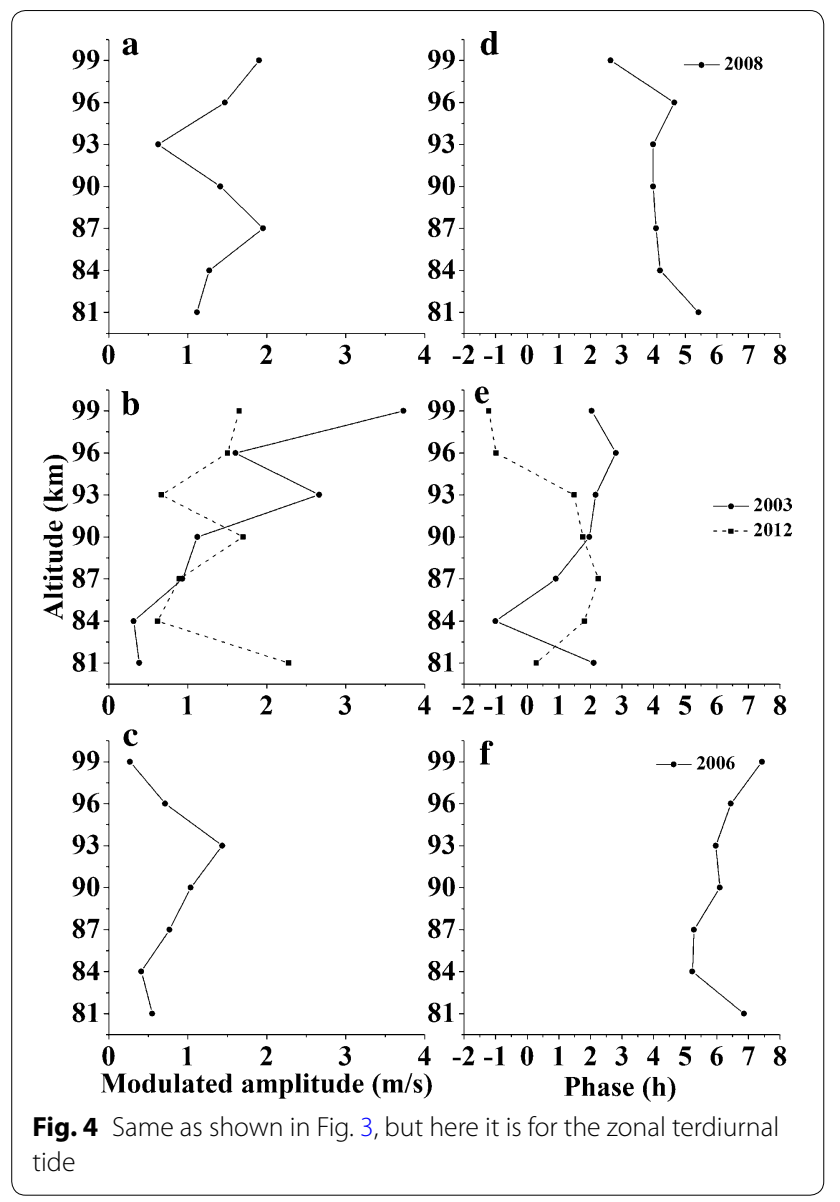

amplitude in the zonal wind and the negative value of the lag indicates the opposite. The positive lag (maximum 13 days) all over the MLT at CA may indicate influence of solar radiation toward the 27-day modulation of the diurnal tide. At $\mathrm{CP}$, the lag profiles are mostly positive except at bottom in 2004. The observed range of the positive lag is $3-18$ days indicating a possibility of wide range of response time of the MLT tides to the solar radiation. Although a positive lag profile is found at SM, small correlation values $(r)$ are unable to ascertain any relationship between the solar flux and MLT tidal oscillation except at 87 and $96 \mathrm{~km}$.

Similar to the previous plot, the $r$ profiles for the semidiurnal tide are shown in Fig. 6a-c. Significantly large correlation $(>0.8)$ is found at CA with a small positive gradient except at the top. At $\mathrm{CP}$, strong correlation is found in 2003 and relatively weaker correlation is observed in 2013 at 84, 93, 96 and $99 \mathrm{~km}$. However, in 2002 no evident correlation can be noted. At SM, appreciable correlation can be observed throughout the range.

The correlation lags corresponding to the semidiurnal tide are shown in Fig. 6d-f. At CA, the lag starts with negative values at the bottom and increases gradually

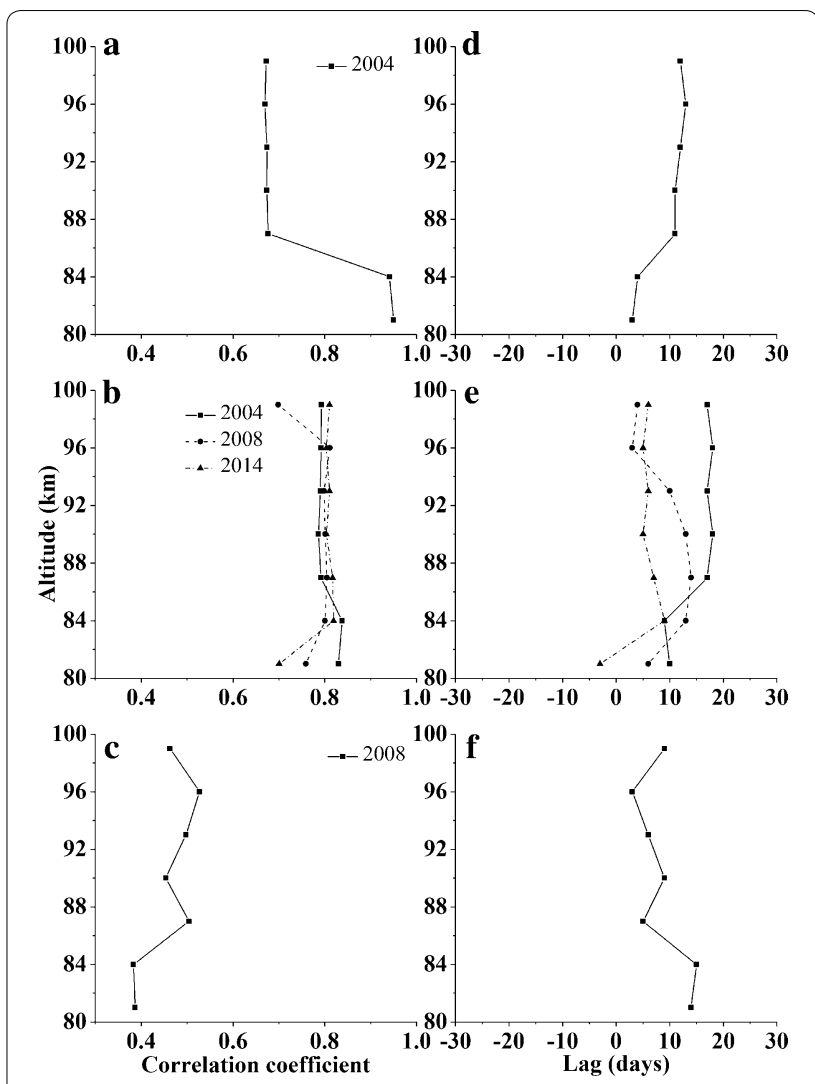

Fig. 5 Cross-correlation coefficient estimated between the filtered solar flux and zonal diurnal tide amplitude at (a) CA, (b) CP and (c) SM Cross-correlation lags are shown at (d) CA, (e) CP and (f) SM

and finally turns to positive in the upper MLT. The large negative lag at lower altitude may indicate the presence of the 27-day modulation of the tides is most probably due to some other source/s that will be discussed in the next section. Notably, long ( $>20$ days) lags are found in 2003 and 2013 indicating slow response of the MLT tides to the solar forcing. Since the correlation is found to be insignificant in 2002, implication of lag values cannot be conceived. At SM, consistent and short positive lags are visible except the upper range $(96-100 \mathrm{~km})$.

In a similar way, the $r$ values for the terdiurnal tides are shown in Fig. $7 \mathrm{a}-\mathrm{c}$. High and almost constant correlation is observed all over the range except $81 \mathrm{~km}$ at CA in 2008 . At $\mathrm{CP}$, appreciable correlation can be found in the range $81-93 \mathrm{~km}$ with a very high correlation around $96-99 \mathrm{~km}$. However, in 2003 no evident correlation is observed. Almost constant and large correlation throughout the range is evident in 2006 at SM.

Figure $7 \mathrm{~d}-\mathrm{f}$ shows the correlation lag profiles of the terdiurnal tide. Small positive lags are evident at mid and top altitudes at CA. At CP, mostly negative lags are present except at top altitudes (96-99 km) in 2012 


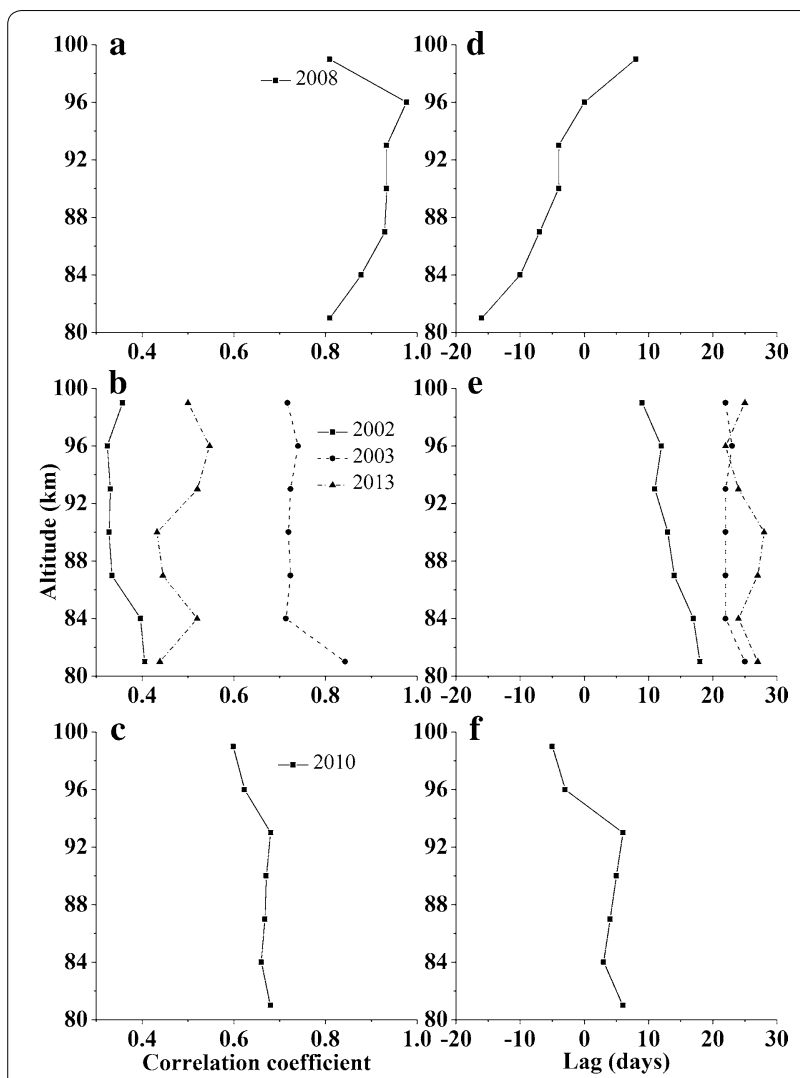

Fig. 6 Same as shown in Fig. 5, but here it is for the zonal semidiurnal tide

corresponding to high $r$ values. On the other hand, sufficiently long positive lags are observed in 2003. However, solar association cannot be deemed herein due to small correlation values. At SM, lags are mostly positive with maximum value of 10 days, except at the top (96-99 km).

\section{Discussions}

A handful of cases of prominent signature of the 27-day modulation in the dominant atmospheric tides in the MLT are found in the long-term meteor wind database from three low-latitude Southern hemispheric stations. The modulation of the tides reveals significant variability in the MLT among various stations. The solar influence on the tidal modulation is investigated. At present, there is hardly any study available that extensively deals with the tidal modulation and solar relationship from the low-latitude region corroborating importance of the present work. Some interesting features as observed in the present study are discussed in view of the plausible mechanisms and agreement/disagreement with the available literatures.

As mentioned earlier, the 27-day oscillation is mostly observed in the tidal amplitudes in the zonal wind (weak
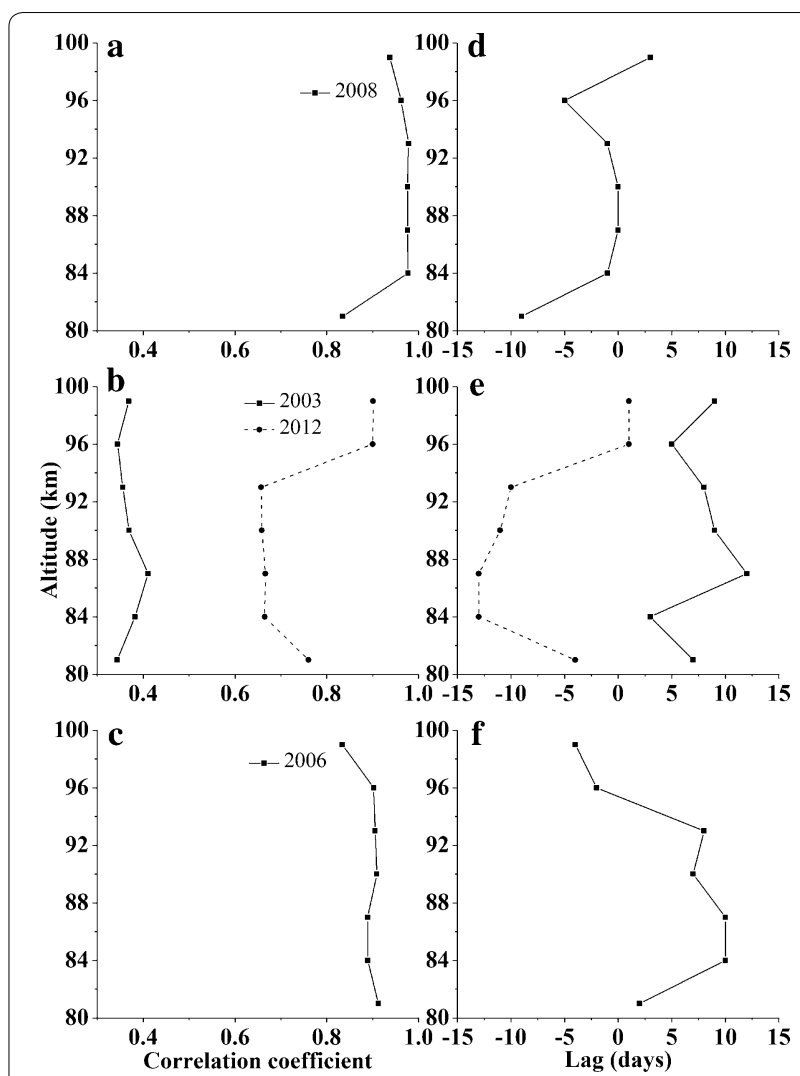

Fig. 7 Same as shown in Fig. 6, but here it is for the zonal terdiurnal tide

and infrequent appearance of the same in the meridional wind) that leads us to focus only on the tidal modulation in the zonal wind. In case of 27-day wind modulation, all the previous studies found strong activity of the concerned oscillation in the zonal wind (Luo et al. 2001; Huang et al. 2015; Guharay et al. 2017). Therefore, major impact of the solar flux variability can be conceived to be on the zonal circulation of the atmosphere and a similar imprint on the tidal amplitudes in the zonal wind can also be deciphered from the present findings.

From the results of the present study, one may note that the 27-day modulation does not take place in all the tidal components simultaneously although the atmospheric tides are primarily driven by the solar radiation due to absorption by the atmospheric species, e.g. water vapor, ozone, etc. The intervals of dominant 27-day modulation of the various tidal components in Table 1 may indicate independent relationship of the tides with the solar radiation which seems to be logically incongruous. The reason for such occurrence is the choice of the events based on the statistical significance of the concerned spectral component. Since the period of the concerned oscillation signature lies well within the intraseasonal oscillation (ISO) 
band, existence of dominant ISO components might suppress the period of our interest at times and as a result, all the three tides may not manifest the 27-day modulation simultaneously. Another reason could be the response mechanisms of the atmospheric species (water vapor, ozone, etc. responsible for tidal excitation) to the solar flux variability that may affect the final tidal response to the solar radiation indirectly.

Naturally, a question arises whether the periodicity is a manifestation of the ISO originating in the lower atmosphere that finally reaches the MLT through gravity waves, planetary waves and tides (Eckermann et al. 1997). Since some of the present cases (out of total 15 cases) exhibit strong correlation (with positive lag) between the solar short-term variability and tidal 27-day modulation, there is a strong implication of solar influence on the tidal variability. However, in the case of longer positive lags, indirect impact of the solar radiation, i.e. first lower atmospheric excitation, and subsequent propagation of the same to the MLT through tides also looks a viable mechanism in addition to the direct excitation. In this context, it should be mentioned that the observed 27-day modulation of the tides over the present sites is not a regular feature. It rather is intermittent appearing in the presence of congenial ambient condition and suitable forcing.

Furthermore, the prominent 27-day variability in the MLT zonal wind can be due to tropospheric convective activities (Huang et al. 2015) or a manifestation of a normal mode inherent in the atmosphere (Andrews et al. 1987; Schanz et al. 2016). In the present study, weak correlation between the solar UV flux variability and MLT tidal modulation is also found at certain intervals. In addition, in some cases, long negative lags (short negative lag to be discussed later) are observed although correlation may be strong. In such cases, it is unlikely that the concerned modulation is directly linked to the solar rotation and hence it could be of lower atmospheric origin as suggested by the previous investigators mentioned above. Utilizing model simulation, Schanz et al. (2016) argued that the 27-day periodicity in the atmosphere should not be linked with the solar rotation as the same could be masked by the dominant inherent mode of the atmosphere, although they admitted that the determination of the actual solar contribution toward this feature to be challenging. Furthermore, they also pointed out a possibility of considerable solar rotational influence on the mesospheric dynamics in winter that seems to be consistent with the present finding.

Recent study by Guharay et al. (2017) from the same locations found an intermittent 27-day feature in the long-term MLT zonal wind and concluded major linkage with the solar UV flux as compared to the lower atmospheric convection. Therefore, from the above discussion, one can interpret that the contribution of the lower atmospheric dynamics cannot be ruled out even in the cases of strong correlation between the modulated tidal amplitudes and solar flux as found in the present work although the lower atmospheric processes are ultimately controlled/modified by the incoming solar radiation.

In a most recent study, Zhao et al. (2019) concluded a prominent manifestation of a Rossby normal mode with the periodicity $\sim 28$ days in winter at high/polar-latitudes and weak feature of the same at mid-latitudes. However, this finding does not seem to be related with the present results due to various reasons: (i) present study is based on low-latitude observations and (ii) the 27-day signature in the current study is found to exist over various seasons in multi-year observations. Ultimately, the previous study indicated a possible role of solar 27-day variability toward excitation of the suspected normal mode consistent with the discussed source mechanism of the present study.

The solar UV flux, utilized in the present study to investigate the solar influence on the tides in the MLT, has a major implication associated to the atmospheric tides. Since the solar UV radiation is effectively absorbed by the ozone in the stratosphere, it has potential to modify the amplitudes of the propagating tides (Ross and Walterscheid 1991). It was also argued that the solar irradiance might not directly modify the MLT dynamics, rather its effect reached there through absorption by the stratospheric ozone (Luo et al. 2001). Using meteor wind observations from a mid-latitude station, Pancheva et al. (2003) indicated a plausible link between the semidiurnal tide in the MLT and the stratospheric ozone in the perspective of the 27-day modulation. Therefore, all the above findings indicate a possible origin of the observed 27-day tidal modulation in the stratosphere due to ozone abundance that reach MLT through the upward progressing tides. Thus, the modulation in the MLT tidal amplitudes as observed in the present study can also be interpreted as an indirect effect of the solar flux via stratospheric excitation.

As mentioned earlier, a few cases in the present study reveal weak correlation between the solar UV flux and MLT tidal modulation that may underestimate the direct solar influence on the observed tidal variability. In addition to the lower atmospheric contribution mentioned before, another possibility for this phenomenon could be a considerable shift of the solar rotational period from the concerned 27-day as it was found to vary within a wide range of 19-33 days (Kane 2002). Furthermore, the corresponding 27-day phase directions show both upward and downward propagation. The upward progression of the phase/oscillation is consistent with the 
previously discussed stratospheric/lower atmospheric influence on the tides. The downward propagation of the corresponding phase may indicate a possible excitation of the concerned oscillation in the ionosphere above ( $\mathrm{Ma}$ et al. 2012). In this context, it is relevant to mention that the ionospheric response to the solar 27-day variability is prompt enough with a delay as short as less than a day (Ren et al. 2018) supporting the plausibility of the observed lag of a few days in the MLT.

Earlier, Pancheva et al. (1991) inferred that the 27-day oscillation in the ionospheric $\mathrm{D}$ region was of direct origin provided the Lyman- $\alpha$ flux bore the same periodic variability. In the present study, the simultaneous existence of the concerned oscillation in both tidal amplitudes and solar Lyman- $\alpha$ flux with short positive lag is consistent with the interpretation of the previous study.

The 27-day modulated tidal amplitudes and corresponding phases exhibit large variability in the MLT. The complexity of such behavior actually depends on the tidal strength, background wind, thermal condition, ambient stability condition, solar flux variability and the associated atmospheric chemistry that could only be addressed through additional and extensive study and beyond the scope of the present work. As depicted before, a few cases of negative lags are observed corresponding to the high correlation. The short negative lags in the cross-correlation analysis may be attributed to the solar influence. In this context, it can be mentioned that Keating et al. (1987) explained the small negative lag $(<3$ days) in the ozone variability in response to the solar short-term UV variability in presence of the temperature feedback mechanism. Although in the present work the investigated parameter is different (tidal amplitude), it may imply an analogous process. In this connection, further extensive study is required to obtain greater details regarding the underlying processes responsible for such peculiar behavior.

\section{Summary}

An evident signature of the intermittent 27-day modulation in the dominant tidal amplitudes (diurnal, semidiurnal and terdiurnal) is found in the MLT using long-term meteor wind data over three Southern hemispheric lowlatitude stations. The influence of the solar rotation on the observed tidal modulation is studied using simultaneous solar Lyman- $\alpha$ flux. Prominent linkage between the tidal modulation and the solar UV radiation is found in a number of cases indicating predominate solar influence in controlling the tidal activities in the MLT. In addition to the direct solar radiation, lower atmospheric dynamics, convective activity, absorption by ozone in the stratosphere, ionospheric absorption of solar radiation, etc. are also surmised to influence the prominent tidal variability in the MLT at times. A few intricate issues, i.e. vertical variation behavior of the modulated tidal amplitude and corresponding phase, long negative lag in concert with high correlation coefficient, etc. as appear, require further coordinated study to improve our current understanding.

\section{Abbreviations}

MLT: Mesosphere and lower thermosphere; CA: São João do Cariri; CP: Cachoeira Paulista; SM: Santa Maria; DY: Day of the year; ISO: Intraseasonal oscillation.

\section{Acknowledgements \\ The Ly-a data provided by the Laboratory for Atmospheric and Space Physics, University of Colorado are available at http://lasp.colorado.edu/lisird/data/ composite_lyman_alpha/. Authors would like to thank the reviewers for useful comments.}

\section{Authors' contributions}

AG conceived the idea and performed analyses related to the present study. PPB carried out radar data processing and also assisted in manuscript preparation. RAB and NJS conducted the operation and data collection of the meteor radar. All authors read and approved the final manuscript.

\section{Funding}

The present work is supported by the Department of Space, Government of India, Conselho Nacional de Desenvolvimento Cientifico e Tecnologio, CNPq, Government of Brazil and Fundação de Amparo á Pesquisa do Estado de São Paulo, Brazil. N.J. Schuch thanks CNPq for the fellowship under Grant Number 300886/2016-0.

\section{Availability of data and materials}

Please contact authors for data request.

\section{Competing interests}

The authors declare that they have no competing interests.

\section{Author details}

${ }^{1}$ Space and Atmospheric Sciences Division, Physical Research Laboratory, Ahmedabad, GJ, India. ${ }^{2}$ Aeronomy Division, National Institute for Space Research, INPE, São José dos Campos, SP, Brazil. ${ }^{3}$ Federal University of Campina Grande, Campina Grande, PB, Brazil. ${ }^{4}$ Southern Regional Space Research Center-CRCRS, COCRE/INPE-MCTIC, Santa Maria, RS, Brazil.

Received: 5 September 2019 Accepted: 11 February 2020

Published online: 29 April 2020

\section{References}

Andrews DG, Holton JR, Leovy CB (1987) Middle atmosphere dynamics. Acad Press, London

Batista PP, Clemesha BR, Tokumoto AS, Lima LM (2004) Structure of the mean winds and tides in the meteor region over Cachoeira Paulista, Brazil $\left(22.7^{\circ} \mathrm{S}, 45^{\circ} \mathrm{W}\right)$ and its comparison with models. J Atmos Sol Terr Phys 66:623-636

Chandra S, McPeters RD (1994) The solar cycle variation of ozone in the stratosphere inferred from Nimbus 7 and NOAA 11 satellites. J Geophys Res 99:20665-20671

Ebel A, Schwister B, Labitzke K (1981) Planetary waves and solar activity in the stratosphere between 50 and 10 mbar. J Geophys Res 86:9729-9738. https://doi.org/10.1029/JC086iC10p09729

Eckermann SD, Rajopadhyaya DK, Vincent RA (1997) Intraseasonal wind variability in the equatorial mesosphere and lower thermosphere: long-term observations from the central Pacific. J Atmos Sol Terr Phys 59:603-627

Füllekrug M, Fraser-Smith AC (1996) Further evidence for a global correlation of the earth-ionosphere cavity resonances. Geophys Res Lett 23:2773-2776 
Guharay A, Franke SJ (2011) Characteristics of the semidiurnal tide in the MLT over Maui $\left(20.75^{\circ} \mathrm{N}, 156.43^{\circ} \mathrm{W}\right)$ with meteor radar observations. J Atmos Sol Terr Phys 73:678-685

Guharay A, Nath D, Pant P, Pande B, Russell JM III, Pandey K (2009) Observation of semiannual and annual oscillation in equatorial middle atmospheric long term temperature pattern. Ann Geophys 27:4273-4280. https://doi. org/10.5194/angeo-27-4273-2009

Guharay A, Batista PP, Clemesha BR, Sarkhel S (2013a) On the variability of the terdiurnal tide over a Brazilian equatorial station using meteor radar observations. J Atmos Sol Terr Phys 104:87-95. https://doi.org/10.1016/j. jastp.2013.08.021

Guharay A, Batista PP, Clemesha BR, Schuch NJ (2013b) Study of the quasi-twoday wave during summer over Santa Maria, Brazil using meteor radar observations. J Atmos Sol Terr Phys 92:83-93. https://doi.org/10.1016/j. jastp.2012.10.005

Guharay A, Batista PP, Clemesha BR (2015) On the variability of the diurnal tide and coupling with planetary waves in the MLT over Cachoeira Paulista (22.7 오 $\left.45^{\circ} \mathrm{W}\right)$. J Atmos Sol Terr Phys 133:7-17. https://doi.org/10.1016/j. jastp.2015.07.016

Guharay A, Batista PP, Buriti RA, Schuch NJ (2017) Signature of the quasi27-day oscillation in the MLT and its relation with solar irradiance and convection. J Atmos Sol Terr Phys 161:1-7. https://doi.org/10.1016/j.jastp .2017 .06 .001

Guharay A, Batista PP, Buriti RA, Schuch NJ (2018) On the variability of the quarter-diurnal tide in the MLT over Brazilian low-latitude stations. Earth Planets Space 70:140. https://doi.org/10.1186/s40623-018-0910-9

Guharay A, Batista PP, Andrioli VF (2019) Investigation of solar cycle dependence of the tides in the low latitude MLT using meteor radar observations. J Atmos Sol Terr Phys 193:105083. https://doi.org/10.1016/j.jastp .2019 .105083

Hagan ME, Forbes JM (2002) Migrating and nonmigrating diurnal tides in the middle and upper atmosphere excited by tropospheric latent heat release. J Geophys Res 107(D24):4754. https://doi.org/10.1029/2001J D001236

Hocking WK, Fuller B, Vandepeer B (2001) Real-time determination of meteorrelated parameters utilizing modern digital technology. J Atmos Sol Terr Phys 63:155-169

Hood LL (1997) The solar cycle variation of total ozone: dynamical forcing in the lower stratosphere. J Geophys Res 102:1355-1370

Hood LL (2016) Lagged response of tropical tropospheric temperature to solar ultraviolet variations on intraseasonal time scales. Geophys Res Lett 43:4066-4075. https://doi.org/10.1002/2016GL068855

Huang KM, Liu AZ, Zhang SD, Yi F, Huang CM, Gan Q, Gong Y, Zhang YH, Wang R (2015) Observational evidence of quasi-27-day oscillation propagating from the lower atmosphere to the mesosphere over $20^{\circ} \mathrm{N}$. Ann Geophys 33:1321-1330. https://doi.org/10.5194/angeo-33-1321-2015

Kane R (2002) Variability in the periodicity of 27 days in solar indices. Sol Phys 209:207. https://doi.org/10.1023/A:1020959817176

Keating GM, Pitts MC, Brasseur G, De Rudder A (1987) Response of middle atmosphere to short-term solar ultraviolet variations. 1. Observations. J Geophys Res 92(D1):889-902

Luo Y, Manson AH, Meek CE, Igarashi K, Jacobi C (2001) Extra long period (20-40 day) oscillations in the mesospheric and lower thermospheric winds: observations in Canada, Europe and Japan, and considerations of possible solar influences. J Atmos Sol Terr Phys 63:835-852

Ma R, Xu J, Wang W, Lei J (2012) The effect of $\sim 27$ day solar rotation on ionospheric $F_{2}$ region peak densities $\left(N_{m} F_{2}\right)$. J Geophys Res 117:A03303. https ://doi.org/10.1029/2011JA017190

Manson AH, Meek CE, Teitelbaum H, Vial F, Schminder R, Kürschner D, Smith MJ, Fraser GJ, Clark RR (1989) Climatologies of semi-diurnal and diurnal tides in the middle atmosphere $(70-110 \mathrm{~km})$ at middle latitudes $\left(40-55^{\circ}\right)$. J Atmos Terr Phys 51:579-593

Miyahara S, Yoshida Y, Miyoshi Y (1993) Dynamic coupling between the lower and upper-atmosphere by tides and gravity waves. J Atmos Terr Phys 55:1039-1053. https://doi.org/10.1016/0021-9169(93)90096-H

Pancheva D, Schminder R, Lastovicka J (1991) 27-day fluctuations in the ionospheric D-region. J Atmos Terr Phys 53:1145-1150

Pancheva D, Mitchell N, Middleton H, Muller H (2003) Variability of the semidiurnal tide due to fluctuations in solar activity and total ozone. J Atmos Sol Terr Phys 65:1-19. https://doi.org/10.1016/S1364-6826(02)00084-6

Ren D, Lei J, Wang W, Burns A, Luan X, Dou X (2018) Does the peak response of the ionospheric F2 region plasma lag the peak of 27-day solar flux variation by multiple days? J Geophys Res Space Phys 123:7906-7916. https:// doi.org/10.1029/2018JA025835

Ross MN, Walterscheid RL (1991) Changes in the solar forced tides caused by stratospheric ozone depletion. Geophys Res Lett 18:420-423

Schanz A, Hocke K, Kämpfer N (2016) On forced and free atmospheric oscillations near the 27-day periodicity. Earth Planets Space 68:97. https://doi. org/10.1186/s40623-016-0460-y

Suh Y-C, Lim G-H (2006) Effects of the 11-year solar cycle on the earth atmosphere revealed in ECMWF reanalyses. Geophys Res Lett 33:L24705. https ://doi.org/10.1029/2006GL028128

Thayaparan T (1997) The terdiurnal tide in the mesosphere and lower thermosphere over London, Canada $\left(43^{\circ} \mathrm{N}, 81^{\circ} \mathrm{W}\right)$. J Geophys Res 102:21695-21708

Thomas GE, Thurairajah B, Hervig ME, von Savigny C, Snow M (2015) Solarinduced 27-day variations of mesospheric temperature and water vapor from the AIM SOFIE experiment: drivers of polar mesospheric cloud variability. J Atmos Sol Terr Phys 134:56-68

Torrence C, Compo G (1998) A practical guide to wavelet analysis. Bull Am Meteorol Soc 79:61-78

von Savigny C, Peters DHW, Entzian G (2019) Solar 27-day signatures in standard phase height measurements above central Europe. Atmos Chem Phys 19:2079-2093. https://doi.org/10.5194/acp-19-2079-2019

Zhao Y, Taylor MJ, Pautet P-D, Moffat-Griffin T, Hervig ME, Murphy DJ et al (2019) Investigating an unusually large 28-day oscillation in mesospheric temperature over Antarctica using ground-based and satellite measurements. J Geophys Res Atmos 124:8576-8593. https://doi. org/10.1029/2019JD030286

\section{Publisher's Note}

Springer Nature remains neutral with regard to jurisdictional claims in published maps and institutional affiliations.

\section{Submit your manuscript to a SpringerOpen ${ }^{\circ}$ journal and benefit from:}

- Convenient online submission

- Rigorous peer review

- Open access: articles freely available online

- High visibility within the field

- Retaining the copyright to your article

Submit your next manuscript at springeropen.com 